\title{
Facile, high efficiency immobilization of lipase enzyme on magnetic iron oxide nanoparticles via a biomimetic coating
}

\author{
Yuhong Ren ${ }^{1 *}$, Jose G Rivera 2,3 , Lihong He ${ }^{2,3}$, Harsha Kulkarni ${ }^{2,3}$, Dong-Keun Lee ${ }^{2,3}$ and \\ Phillip B Messersmith $2,3,4,5,6,7^{*}$
}

\begin{abstract}
Background: Immobilization of lipase on appropriate solid supports is one way to improve their stability and activity, and can be reused for large scale applications. A sample, cost- effective and high loading capacity method is still challenging.

Results: A facile method of lipase immobilization was developed in this study, by the use of polydopamine coated magnetic nanoparticles (PD-MNPs). Under optimal conditions, 73.9\% of the available lipase was immobilized on PDMNPs, yielding a lipase loading capacity as high as $429 \mathrm{mg} / \mathrm{g}$. Enzyme assays revealed that lipase immobilized on PD-MNPs displayed enhanced pH and thermal stability compared to free lipase. Furthermore, lipase immobilized on PD-MNPs was easily isolated from the reaction medium by magnetic separation and retained more than $70 \%$ of initial activity after 21 repeated cycles of enzyme reaction followed by magnetic separation.
\end{abstract}

Conclusions: Immobilization of enzyme onto magnetic iron oxide nanoparticles via poly-dopamine film is economical, facile and efficient.

\section{Background}

Lipases (glycerol ester hydrolases E.C.3.1.1.3) are an important group of enzymes which have been widely used in the catalysis of different reactions [1,2]. These enzymes have been applied in chemical and pharmaceutical industrial applications due to their catalytic activity in both hydrolytic and synthetic reactions. However, free lipases are easily inactivated and difficult to recover for reuse. Therefore, especially in large-scale applications, lipases are often immobilized on solid supports in order to facilitate recovery and improve operational stability under a wide variety of reaction conditions. Some lipase immobilization strategies involve the conjugation of lipases via covalent attachment, cross-linking, adsorption and entrapment onto hydrophobic or hydrophilic polymeric and inorganic matrixes [3-5].

\footnotetext{
* Correspondence: yhren@ecust.edu.cn; philm@northwestern.edu 'State Key Laboratory of Bioreactor Engineering, East China University of Science and Technology, 130 Meilong Road, Shanghai 200237, China ${ }^{2}$ Biomedical Engineering Department, Northwestern University, 2145 Sheridan Road, Evanston 60208, USA

Full list of author information is available at the end of the article
}

In recent years, magnetic nanoparticles (MNPs) based on iron oxides, have attracted much interest thanks to their multifunctional properties, such as biocompatibility, superparamagnetism, small size and low toxicity [6]. They have been applied in magnetic resonance imaging (MRI) [7], biosensors [8] and as anti-cancer drugs carriers [9]. Due to their high specific surface area and easy separation from the reaction medium by the use of a magnet, they have been employed in enzymatic catalysis applications $[10,11]$. Typical strategies for immobilizing lipase onto MNPs rely on surface grafting via low molecular weight linkers or polymers containing amino or epoxy functional groups to which lipases are reacted via covalent conjugation methods $[1,11]$. Using such methods, the maximum reported loading capacity of lipase on nanoparticles is approximately $130 \mathrm{mg} / \mathrm{g}$, using a complex methodology [1]. One drawback of existing lipase immobilization technologies is that the activity of lipases decreases significantly upon immobilization due possibly to changes in enzyme secondary structure, or limited access of substrate to the active site of the surface bound enzyme [12]. Thus, despite numerous reported approaches for immobilization

\section{C)


of lipases on magnetic nanoparticles, there is still the need for simple, cost-effective and high loading capacity methods.

In this work, we present a facile, biomimetic approach to immobilize lipases onto iron oxide MNP surfaces modified with polydopamine, an in-situ formed coating inspired by the adhesive proteins secreted by marine mussels [13]. The ortho-dihydroxyphenyl (catechol) functional group found in dopamine is also present in mussel adhesive proteins in the form of the amino acid DOPA, where it is highly adhesive to oxide surfaces $[14,15]$ and under alkaline conditions oxidizes to form quinone, a species that is reactive toward nucleophiles such as primary amines. Dopamine, containing both catechol and primary amine, was previously found to produce conformal coatings on surfaces by self-polymerization [13], which are further capable of immobilizing biomolecules [15]. In the method described here, polydopamine serves as a conformal coating for the purposes of lipase immobilization onto MNPs. Our results demonstrate that PD-MNPs exhibit high efficiency for lipase immobilization under aqueous conditions, and the enzyme retains high activity after many cycles of magnetic separation and reuse.

\section{Results and discussion}

\section{Overall Strategy for Preparing Lipase Immobilized Iron} Oxide MNPs

Our two-step method of polydopamine surface modification and lipase immobilization is illustrated in Figure 1. Iron oxide MNPs prepared by alkaline co-precipitation of $\mathrm{Fe}(\mathrm{II})$ and $\mathrm{Fe}(\mathrm{III})$ were first incubated in an alkaline dopamine solution for several hours to create an adherent polydopamine film on MNPs (PD-MNPs), after which enzyme was immobilized by exposure of PD-MNPs to a lipase containing solution.

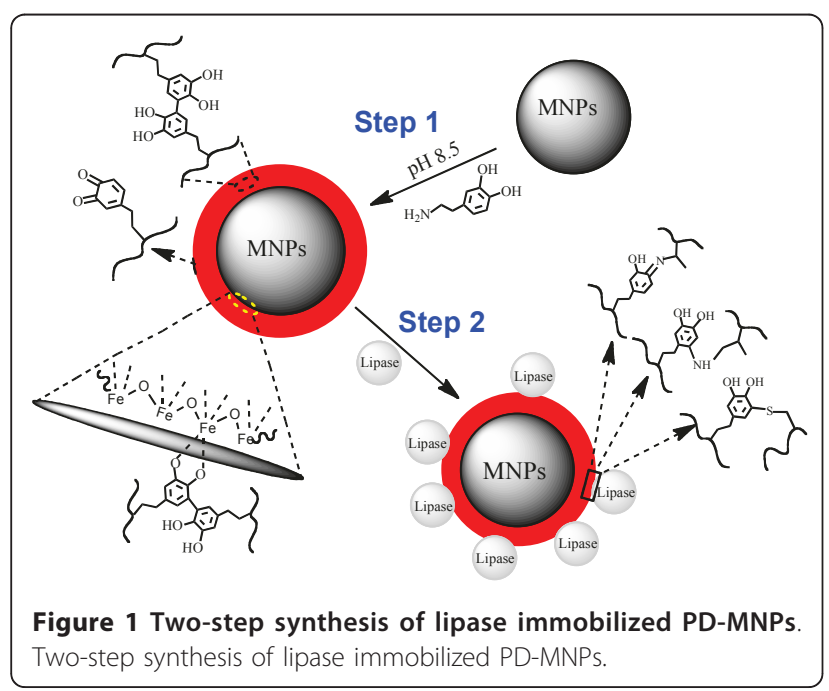

Synthesis and characterization of MNPs and PD-MNPs

Catechol derivatized polymers have been previously employed for grafting functional polymers onto surfaces of MNPs [16-18]. In the present work we took advantage of dopamine self-polymerization to form MNPs with polydopamine coatings. In-situ polymerization of dopamine represents a versatile method for modifying solid surfaces with adherent coatings for a variety of functional purposes [13]. The reactions that occur in an alkaline dopamine solution are not unlike those that occur during melanin formation, beginning with oxidation of catechol to yield dopamine quinone, which in turn participates in a series of further intra- and intermolecular reactions that ultimately give rise to a high molecular weight heterogeneous polymer (polydopamine). Polydopamine formation occurs both in solution and as a conformal coating on surfaces. In the present case involving iron oxide MNPs, the polydopamine is likely bound to the surface and even nucleated by dopamine molecules that strongly interact with the oxide surface [14].

X-ray photoelectron spectroscopy (XPS) spectra of the MNPs and PD-MNPs are shown in Figure 2. Whereas the unmodified MNPs contained little carbon and nitrogen content (Figure 2A), the XPS spectrum of PDMNPs contained prominent peaks correlating to $\mathrm{C} 1 \mathrm{~s}$ $(284.5 \mathrm{eV})$ and N1s (399.5 eV) (Figure 2B). The calculated nitrogen-to-carbon $(\mathrm{N} / \mathrm{C})$ ratio of the PD-MNPs is 0.119 , which is close to the theoretical N/C of 0.125 for dopamine. Additionally, the Fe 2p (711 and $724.5 \mathrm{eV}$ ) peaks are attenuated in PD-MNPs compared to MNPs due to the presence of the polydopamine coating. Further evidence for polydopamine coating is provided by a shift of the O1s peak from $529.5 \mathrm{eV}$ in MNPs and corresponding to iron oxide, to $532 \mathrm{eV}$ corresponding to organic oxygen.

The size and morphology of the MNPs and the PDMNPs were observed by SEM and TEM (Figure 3A and 3B). The unmodified MNPs were composed of clusters of nanoparticles with sizes ranging from $5 \mathrm{~nm}$ to $15 \mathrm{~nm}$. In comparison, SEM and TEM images of the PD-MNPs reveal aggregates iron oxide particles entrapped in a conformal polydopamine coating of approximate thickness $10 \mathrm{~nm}$. The average size of the PD-MNPs agglomerates ranged from $50 \mathrm{~nm}$ to $250 \mathrm{~nm}$. Although some observed aggregation could be caused by drying during TEM sample preparation [19], it is also possible that polydopamine induced partial aggregation of MNP clusters.

Magnetic isolation of PD-MNPs was accomplished by placing a magnet adjacent to a vial containing PDMNPs dispersed in an aqueous medium (Figure 4). Within two minutes the solution became clear as a result of movement of the PD-MNPs towards the 


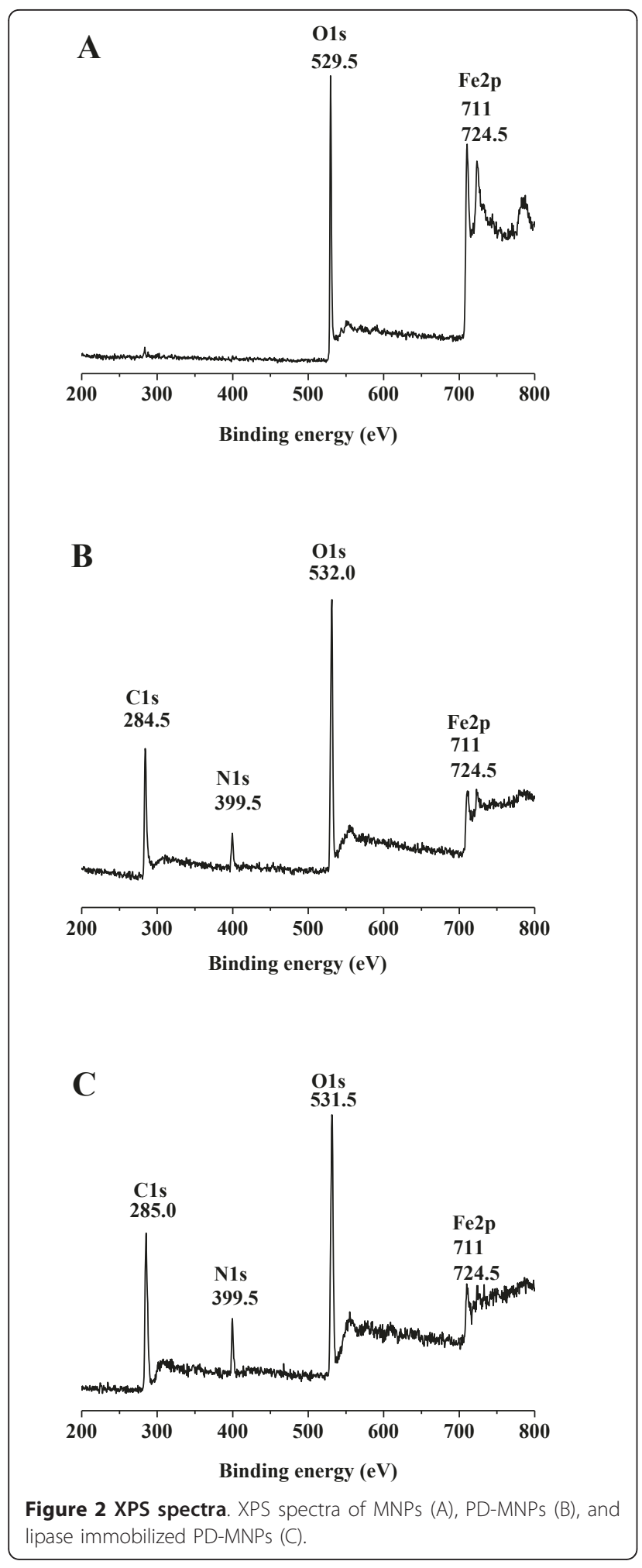

magnet, demonstrating simple and rapid isolation of PD-MNPs using a magnetic field. Removal of the magnet followed by agitation led to re-suspension of the PD-MNPs.

\section{Lipase immobilization onto PD-MNPs}

After formation, the polydopamine coating contains residual quinones that are reactive toward nucleophilic groups, affording covalent immobilization of polymers and biomolecules through Michael addition and/or Schiff base formation $[13,15]$. In the present case, similar reactions between the active quinone groups at the surface of the PD-MNPs and the amino or thiol groups of the lipase enzyme result in lipase immobilization onto the surfaces of the PD-MNPs during the lipase immobilization step (Figure 1). The reaction between PD-MNPs and lipase was spontaneous and rapid, resulting in precipitation of lipase-containing MNPs particles soon after mixing. Analysis of free protein concentration in solution during lipase immobilization at $4^{\circ} \mathrm{C}$ showed little change after 2 hours, further confirming the completion of the immobilization reaction.

XPS analysis of the lipase immobilized PD-MNPs (Figure 2C) showed increases in the N1s peak $(399.5 \mathrm{eV})$ and the calculated N/C ratio (0.139) compared to PDMNPs, reflecting the higher nitrogen content of lipase compared to polydopamine. Little change in aggregate appearance and morphology was observed upon immobilization of lipase onto PD-MNPs, although SEM and TEM analysis (Figure 3C) revealed further agglomeration (average size $150-250 \mathrm{~nm}$ ). It is not known whether the additional aggregation occurred during lipase immobilization or was an artifact of EM sample preparation.

Lipase immobilization efficiency as well as the activity of bound enzyme was found to be dependent on conditions used during preparation of PD-MNPs and immobilization of lipase (Table 1). In the absence of polydopamine treatment, binding of lipase to MNPs was inefficient and resulted in low activity. Through the use of polydopamine, the amount of bound lipase was increased by as much as 3 -fold. Increasing the concentration of dopamine used in preparing the PD-MNPs in the range $0.25-2.5 \mathrm{mg} / \mathrm{ml}$ resulted in an increase in bound lipase from $6.96 \mathrm{mg}$ to $9.16 \mathrm{mg}$ coupled with an increase in enzyme specific activity from 2.62 to $6.44 \mathrm{U} /$ $\mathrm{mg}$. These results show that polydopamine is essential for immobilization of high amounts of lipase enzyme onto MNPs. However, taking into consideration the cost of enzyme and that specific activity of bound lipase did not significantly increase above initial dopamine concentration of $2.5 \mathrm{mg} / \mathrm{ml}$, we identified optimum conditions to be polydopamine deposition at $2.5 \mathrm{mg} / \mathrm{ml}$ dopamine concentration followed by lipase immobilization at a 2:1 $(\mathrm{w} / \mathrm{w})$ ratio of PD-MNPs to lipase. Under these conditions we achieved a lipase loading of $429 \mathrm{mg} / \mathrm{g}$ of material (85.8\% of the amount of added lipase) with $8.78 \mathrm{U} /$ mg specific activity (73.9\% of free lipase specific activity), much higher than previous reports [1]. 

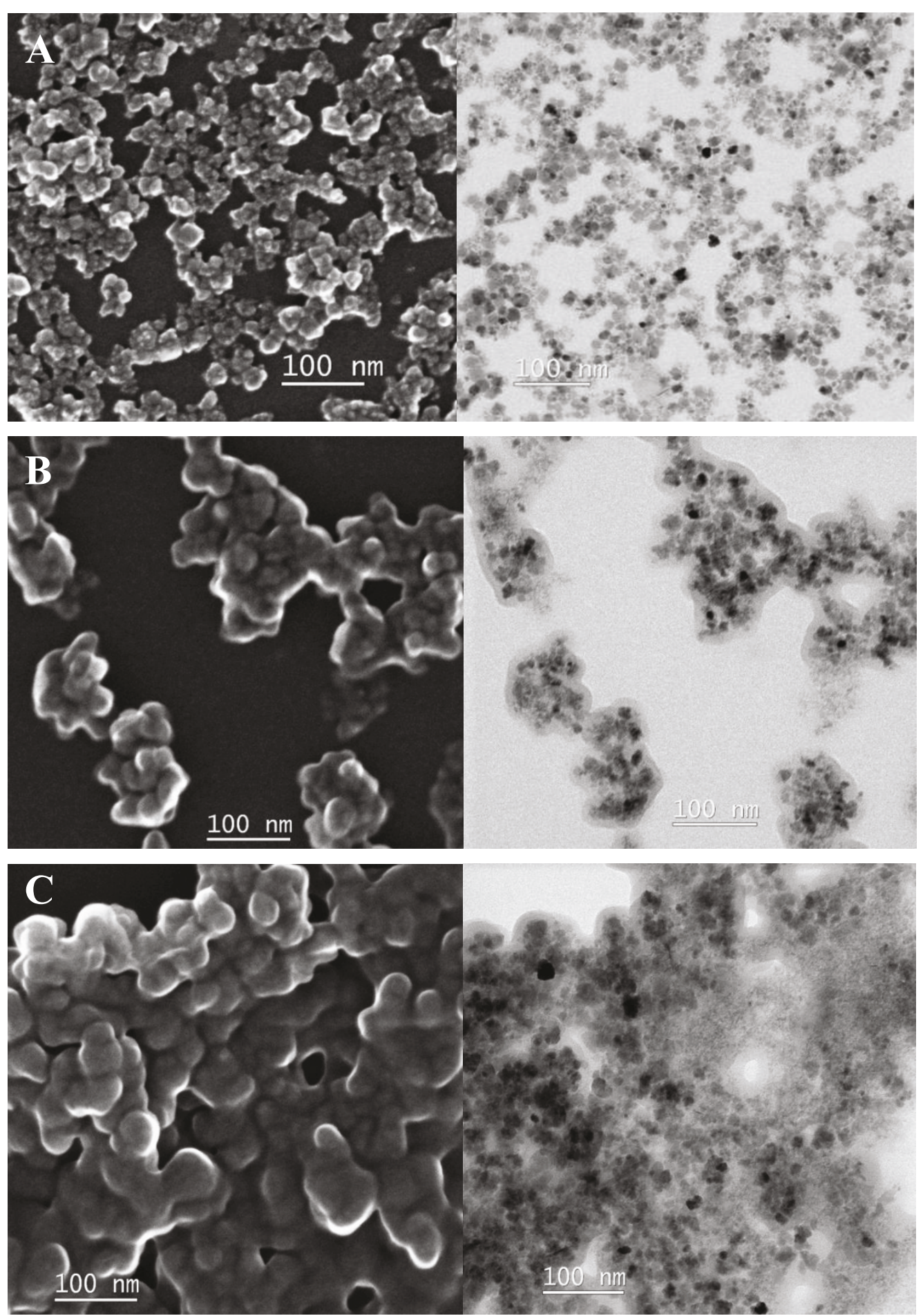

Figure 3 SEM and TEM spectra. SEM (left column) and TEM (right column) images of MNPS (A), PD-MNPs (B), and lipase immobilized PD-MNPs (C). The PD-MNPs were prepared using $2.5 \mathrm{mg} / \mathrm{ml}$ initial dopamine and lipase immobilization performed using $5 \mathrm{mg} / \mathrm{ml}$ initial lipase and $10 \mathrm{mg} /$ $\mathrm{ml}$ PD-MNPs concentration. 


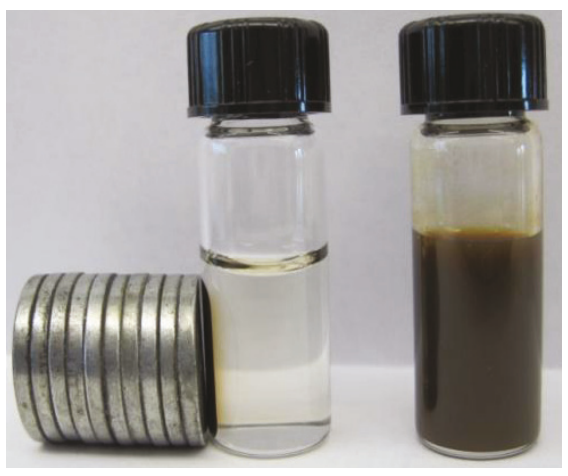

Figure 4 Magnetic isolation of PD-MNP. Photographs of an aqueous suspension of PD-MNPs before (right) and after (left) magnetic isolation.

\section{Effect of temperature and $\mathrm{pH}$ on free and immobilized} lipase activity

The effect of temperature on the activity of free and immobilized lipase at $\mathrm{pH} 7.0$ is shown in Figure 5. The activity of both free and immobilized lipase is not adversely affected at temperatures below $40^{\circ} \mathrm{C}$. The relative activity of free lipase dropped significantly above $40^{\circ}$ $\mathrm{C}$ and decreased to just $26.5 \%$ of the initial activity at $60^{\circ} \mathrm{C}$. In comparison, lipase immobilized on PD-MNPs retained $59.3 \%$ of activity at $60^{\circ} \mathrm{C}$. A possible explanation for this is enhanced thermal stability in the immobilized state, leading to less denaturation of protein [10].

The effect of $\mathrm{pH}$ on the relative activity of free and immobilized lipase is shown in Figure 6. According to our data, the activity of lipase immobilized on PDMNPs was retained throughout a wider $\mathrm{pH}$ range compared to free enzyme. At pH 6-7, free lipase was stable for short incubation periods but was adversely affected at longer incubation times, retaining only $60-70 \%$ of the activity after $96 \mathrm{~h}$ incubation. At $\mathrm{pH} 5$ and 8 only 30$40 \%$ of the activity of the free enzyme was retained after $96 \mathrm{~h}$, and complete loss in activity was observed for free lipase upon incubation at $\mathrm{pH} 4$ and 9. In contrast, PD- lipase immobilized on MNPs retained more than $90 \%$ of activity at pH 6 and 7, and even retained more than $50 \%$ of activity after 96 hours incubation at $\mathrm{pH} 4,5$ and 8. The increased stability of immobilized lipase may result from multipoint covalent linking between lipase and the PD-MNPs, which prevents lipase denaturation in acid or alkaline environments [10,20].

\section{Magnetic Isolation and Reuse}

Reuse of enzymes in industrial processes is advantageous from an economic point of view. We therefore investigated this feature in lipase immobilized PDMNPs, whose magnetic properties and enhanced enzyme stability were designed to facilitate multiple cycles of magnetic isolation and reuse. Figure 7 shows the activity of lipase immobilized PD-MNPs after multiple cycles of magnetic separation and reuse. Although the activity of the immobilized lipase began to decrease after 4 cycles, more than $70 \%$ of its initial activity was still retained after 21 cycles. The decrease of activity may be caused by aggregation and loss of particles during magnetic isolation, denaturation of protein and the gradual loss of lipase from the PD-MNPs.

\section{Conclusions}

In this work, we described a facile method to immobilize lipase onto magnetic nanoparticles through an adhesive polydopamine film. Our immobilization experiments show that the PD-MNPs exhibit high lipase loading capacity due to high surface area and strong adhesive interactions between lipase and polydopamine. In addition, the immobilized lipase shows high specific activity and favorable thermal and $\mathrm{pH}$ stability compared to free lipase. Importantly, the lipase immobilized PD-MNPs display good reusability as well as the convenience to be magnetically recovered. These results confirm that immobilization of enzyme onto magnetic iron oxide nanoparticles by poly-dopamine film, is economical, facile and efficient.

Table 1 Effect of preparation conditions on lipase immobilization efficiency and activity of lipase immobilized PD-MNP

\begin{tabular}{cccccc}
\hline $\begin{array}{c}\text { Dopamine } \\
(\mathbf{m g} / \mathbf{m l})\end{array}$ & $\begin{array}{c}\text { PD-MNP } \\
(\mathbf{m g})\end{array}$ & Lipase $(\mathbf{m g})$ & Bound Lipase $(\mathbf{m g})$ & $\begin{array}{c}\text { Activity } \\
(\mathbf{U})\end{array}$ & Specific Activity (U/mg lipase) \\
\hline 0 & 10 & 10 & $3.16 \pm 0.52$ & $9.75 \pm 2.28$ & $3.09 \pm 0.16$ \\
0.25 & 10 & 10 & $6.96 \pm 0.49$ & $18.19 \pm 2.90$ & $2.62 \pm 0.13$ \\
0.5 & 10 & 10 & $7.81 \pm 0.62$ & $21.08 \pm 2.49$ & $2.70 \pm 0.17$ \\
1.0 & 10 & 10 & $8.26 \pm 0.48$ & $28.81 \pm 3.08$ & $3.49 \pm 0.17$ \\
2.5 & 10 & 10 & $9.17 \pm 0.58$ & $59.00 \pm 3.39$ & $6.44 \pm 0.38$ \\
3.75 & 10 & 10 & $9.37 \pm 0.55$ & $62.50 \pm 3.04$ & $6.67 \pm 0.37$ \\
5.0 & 10 & 10 & $9.46 \pm 0.57$ & $64.89 \pm 2.69$ & $6.86 \pm 0.40$ \\
2.5 & 10 & 5 & $4.29 \pm 0.22$ & $37.65 \pm 2.52$ & $8.78 \pm 0.33$ \\
Free lipase & & 10 & & $118.76 \pm 4.13$ & $11.88 \pm 0.41$ \\
\hline
\end{tabular}

Effect of preparation conditions on lipase immobilization efficiency and activity of lipase immobilized PD-MNP $(n=3)$. 


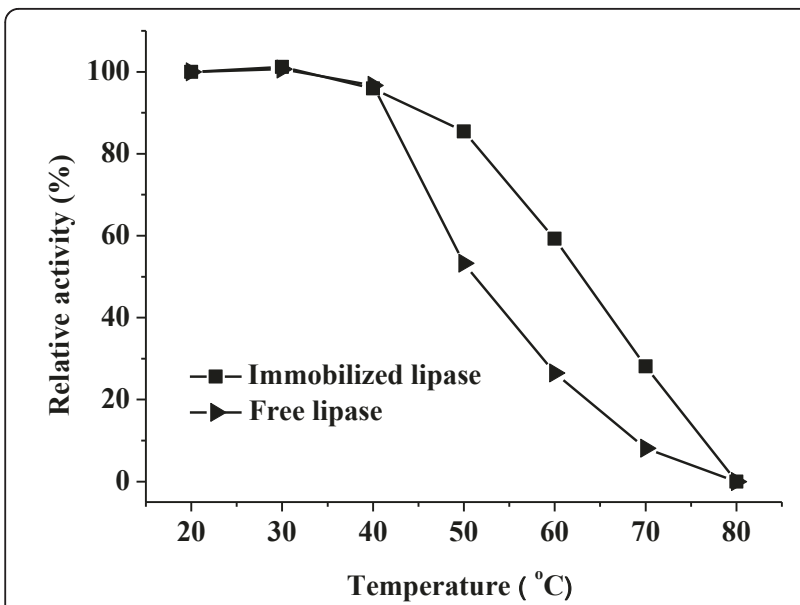

Figure $\mathbf{5}$ The effect of temperature on the activity of free and immobilized lipase. Activity was measured at $37^{\circ} \mathrm{C}$ after treatment for 1 hour in phosphate buffer $(10 \mathrm{mM}, \mathrm{pH} 7.0)$ at the temperatures indicated. The PD-MNPs were prepared using $2.5 \mathrm{mg} / \mathrm{ml}$ initial dopamine and lipase immobilization performed using $5 \mathrm{mg} / \mathrm{ml}$ initial lipase and $10 \mathrm{mg} / \mathrm{ml}$ PD-MNPs concentration.

\section{Methods \\ Materials}

Candida rugosa lipase type VII (E.C.3.1.1.3), ferric chloride hexahydrate $\left(\mathrm{FeCl}_{3} \cdot 6 \mathrm{H}_{2} \mathrm{O}\right)$, ferrous chloride tetrahydrate $\left(\mathrm{FeCl}_{2} \cdot 4 \mathrm{H}_{2} \mathrm{O}\right)$, dopamine hydrochloride, tributyrin, gum acacia, tris buffer and sodium hydroxide were purchased from Sigma-Aldrich (USA). Ultrapure water (resistivity $=18.2 \mathrm{M} \Omega, \mathrm{pH}$ 6.82) was used in all experiments and obtained from a NANOpure Infinity ${ }^{@}$ system from Barnstead/Thermolyne Corporation (Dubuque, IA).

\section{Synthesis and surface modification of MNPs}

Figure 1 presents the synthesis and modification of MNPs. MNPs were prepared by the conventional coprecipitation method [21] with some modifications. Briefly, $0.5 \mathrm{mmol} \mathrm{FeCl}_{2}$ and $1.0 \mathrm{mmol} \mathrm{FeCl}_{3}$ were dissolved in $50 \mathrm{ml}$ ultrapure water under nitrogen at room temperature, then the $\mathrm{pH}$ of the solution was adjusted to 10.0 using $6.0 \mathrm{M} \mathrm{NaOH}$ under vigorous stirring. After stirring for 2 hours, the magnetite precipitates were separated and washed several times with ultrapure water by magnetic decantation. The precipitate was dispersed in $50 \mathrm{ml}$ Tris buffer $(10 \mathrm{mM}, \mathrm{pH} 8.5)$ under ultrasonication for $15 \mathrm{~min}$, after which large precipitates were removed. Dopamine hydrochloride $(125 \mathrm{mg}, 2.5$ $\mathrm{mg} / \mathrm{ml}$ ) was added to the remaining MNPs suspension with vigorous stirring, and the $\mathrm{pH}$ of the solution was kept at 8.5 by addition of $10 \mathrm{mM} \mathrm{NaOH}$. After 3 hours, the PD-MNPs was collected by magnetic decantation and washed 5 times with ultrapure water, and finally re-
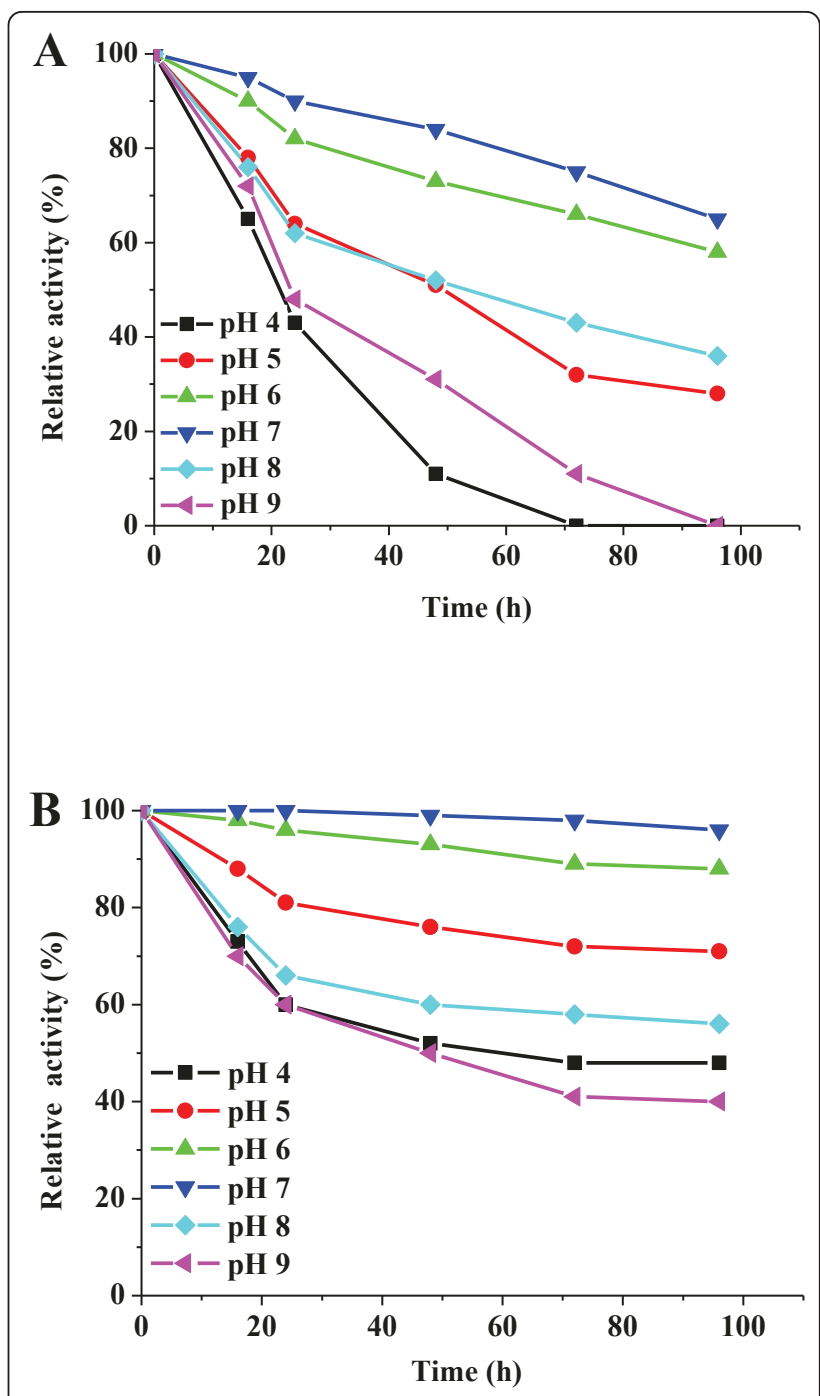

Figure 6 The effect of $\mathrm{pH}$ on the activity of free and immobilized lipase. The effect of $\mathrm{pH}$ on the activity of free (A) and immobilized (B) lipase. The samples were pre-incubated in phosphate buffer $(10 \mathrm{mM})$ at the $\mathrm{pH}$ values and times indicated before determining enzyme activity at $\mathrm{pH} 7.0$ and $37^{\circ} \mathrm{C}$. The PDMNPs were prepared using $2.5 \mathrm{mg} / \mathrm{ml}$ initial dopamine and lipase immobilization performed using $5 \mathrm{mg} / \mathrm{ml}$ initial lipase and $10 \mathrm{mg} /$ $\mathrm{ml}$ PD-MNPs concentration.

dispersed in ultrapure water to $2 \mathrm{mg}$ PD-MNPs per milliliter solution by ultrasonication for $15 \mathrm{~min}$.

\section{Immobilization of lipase}

Lipase immobilization was carried out by adding the suspension of PD-MNPs in ultrapure water to a buffered enzyme solution. An aqueous solution of lipase $(2 \mathrm{mg} /$ $\mathrm{ml}$ ) was prepared by dissolving the lyophilized enzyme in sodium phosphate buffer $(10 \mathrm{mM}, \mathrm{pH}$ 7.0) solution. A fresh solution of the previously described PD-MNPs $(5 \mathrm{ml}, 2 \mathrm{mg} / \mathrm{ml})$ was added to the lipase solution $(5 \mathrm{ml}$, 


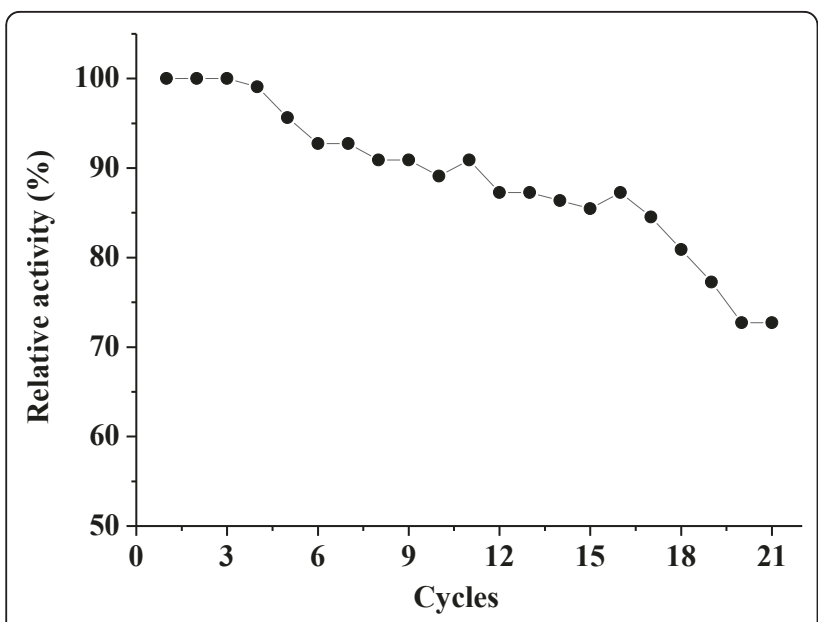

Figure 7 The activity of immobilized lipase after multiple cycles of magnetic isolation and reuse. Activity of lipase immobilized PD-MNPs after multiple cycles of magnetic isolation and reuse. The PD-MNPs were prepared using $2.5 \mathrm{mg} / \mathrm{ml}$ initial dopamine and lipase immobilization performed using $5 \mathrm{mg} / \mathrm{ml}$ initial lipase and $10 \mathrm{mg} / \mathrm{ml}$ PD-MNPs concentration. The total elapsed time of the experiment was less than 10 hours.

$2 \mathrm{mg} / \mathrm{ml}$ ) at $4^{\circ} \mathrm{C}$. Precipitation was observed immediately as the two solutions mixed. After shaking at $180 \mathrm{rpm}$ for $3 \mathrm{~h}\left(\right.$ at $\left.4^{\circ} \mathrm{C}\right)$, the lipase-loaded precipitates were collected and washed 3 times with ultrapure water and stored at $4^{\circ} \mathrm{C}$ prior to use. The protein concentration in the lipase solution before and after immobilization was determined using the Bradford method [22]. The difference in protein concentration was used to calculate the loading of lipase onto the PD-MNPs.

\section{Characterization of MNPs and PD-MNPs}

XPS spectra were obtained using an Omicron ESCALAB (Omicron, Taunusstein, Germany) with a monochromatic Al Ka (1486.8 eV) 300-W X-ray source, a flood gun to counter charging effects, and ultrahigh vacuum $\left(\sim 10^{-9}\right.$ torr $)$. The takeoff angle was fixed at $45^{\circ}$. Substrates were mounted on sample studs by means of double-sided adhesive tape. All binding energies were calibrated using the $\mathrm{C} 1$ s peak $(284.5 \mathrm{eV})$. Scanning electron microscopy (SEM) and transmission electron microscopy (TEM) images were acquired on a Hitachi HD2300 electron microscope (Hitachi, Japan) operated at $200 \mathrm{kV}$. TEM specimens were prepared by casting drops of dilute dispersion of nanoparticles aqueous solution on 200-mesh carbon coated copper grids (Ted Pella).

\section{Activity assay of free and immobilized lipase}

The enzymatic activities of free and immobilized lipase were measured by titration of the organic acid that results from the hydrolysis of the tributyrin ester [23].
Briefly, the activity of the free lipase was assayed by adding $0.5 \mathrm{ml}$ of free lipase $(5 \mathrm{mg} / \mathrm{ml}, \mathrm{w} / \mathrm{v})$ in phosphate buffer (10 mM, pH 7.0), $20 \mathrm{ml}$ of a tributyrin solution consisting of $1 \%$ tributyrin as the substrate with $1 \%$ gum acacia as emulsifier. After $20 \mathrm{~min}$ of incubation at $37^{\circ} \mathrm{C}$ with shaking at $150 \mathrm{rpm}$, the reaction was stopped by the addition of $20 \mathrm{ml}$ of ethanol. Immediately, the mixture was titrated against $50 \mathrm{mM} \mathrm{NaOH}$ in ethanol solution using phenolphthalein as indicator. The immobilized lipase activity was determined as described above by adding a known amount of lipase immobilized PDMNPs. The lipase loaded PD-MNPs were sonicated for $10 \mathrm{~min}$ at $4^{\circ} \mathrm{C}$ before combining with substrate solution. After incubation of the mixture at $37^{\circ} \mathrm{C}$ for $20 \mathrm{~min}$ with shaking at $200 \mathrm{rpm}$, the lipase PD-MNPs were separated by a magnet, and the supernatant titrated using an $\mathrm{NaOH}$ in ethanol solution. One unit of lipase activity was defined as the amount of lipase which liberated $1 \mu \mathrm{mol}$ of free acid per minute under the assay conditions. All activity measurements were carried out at least three times and the experimental error was less than $3 \%$.

\section{Effect of temperature and $\mathrm{pH}$}

The effect of temperature on the free and immobilized enzyme activity was determined by pre-incubating in phosphate buffer $(10 \mathrm{mM}, \mathrm{pH}$ 7.0) at temperatures ranging from $20^{\circ} \mathrm{C}$ to $80^{\circ} \mathrm{C}$ for $1 \mathrm{~h}$, followed by measurement of the residual enzyme activity at $37^{\circ} \mathrm{C}$ as described above. The effect of $\mathrm{pH}$ on the activity of the free and immobilized enzyme was determined by preincubating at room temperature in phosphate buffer $(10 \mathrm{mM})$ at $\mathrm{pH}$ ranging from 4 to 9 , followed by determination of enzymatic activity at pH 7.0 as described in activity assay section. The residual activity of the immobilized lipase was normalized to the initial value determined at $37^{\circ} \mathrm{C}, \mathrm{pH} 7.0$ (the initial activity was defined as $100 \%)$.

\section{Recovery and reuse of immobilized lipase}

The stability of immobilized lipase under conditions of repeated magnetic isolation and reuse was studied under the same conditions as described in activity assay section. After each enzyme run, the lipase containing PDMNPs were magnetically isolated and washed twice with hexane and ultrapure water to remove any remaining substrate and product species before the next experiment. The residual activity of the immobilized lipase after each cycle was normalized to the initial value (the initial activity was defined as $100 \%$ ).

\section{Acknowledgements}

This research was partially supported by grant R37 DE 014193 from the National Institutes of Health. 


\section{Author details}

'State Key Laboratory of Bioreactor Engineering, East China University of Science and Technology, 130 Meilong Road, Shanghai 200237, China. ${ }^{2}$ Biomedical Engineering Department, Northwestern University, 2145 Sheridan Road, Evanston 60208, USA. ${ }^{3}$ Chemistry of Life Processes Institute, Northwestern University, 2145 Sheridan Road, Evanston 60208, USA. ${ }^{4}$ Chemical and Biological Engineering Department, Northwestern University, 2145 Sheridan Road, Evanston 60208, USA. ${ }^{5}$ Materials Science and Engineering Department, Northwestern University, 2145 Sheridan Road, Evanston 60208, USA. 'Institute for Bionanotechnology in Medicine, Northwestern University, 2145 Sheridan Road, Evanston 60208, USA. ${ }^{7}$ Robert H. Lurie Comprehensive Cancer Center, Northwestern University, 2145 Sheridan Road, Evanston 60208, USA.

\section{Authors' contributions}

YR preformed most of experiments, participated in all data analysis, and drafted much of the manuscript. JGR, LH and DKL provided regular advice as the study progressed. HK preformed XPS experiments. PBM conceived of the study, participated in all data analysis, and drafted parts of the manuscript. All authors read and approved the final manuscript.

Received: 20 January 2011 Accepted: 8 June 2011

Published: 8 June 2011

\section{References}

1. Wu Y, Wang YJ, Lou GS, Dai YY: In situ preparation of magnetic Fe3O4chitosan nanoparticles for lipase immobilization by cross-linking and oxidation in aqueous solution. Bioresource Technol 2009, 100:3459-3464.

2. Petkar M, Lali A, Caimi P, Daminati M: Immobilization of lipase for nonaqueous synthesis. J Mol Catal B Enzym 2006, 39:83-90.

3. Chen YZ, Ching $C B, X u$ R: Lipase immobilization on modified zirconia nanoparticles: Studies on the effects on modifiers. Precess Biochem 2009, 44:1245-1251

4. Cao LQ: Immobilised enzymes: science or art? Curr Opin Chem Biol 2005, 9:217-226.

5. Mateo C, Palomo JM, Fernandez-Lorente G, Guisan JM, FernandezLafuente R: Improvement of enzyme activity, stability and selectivity via immobilization techniques. Enzyme Microb Technol 2007, 40:1451-1463.

6. Duguet $E$, Vasseur $S$, Mornet $S$, Devoisselle JM: Magnetic nanoparticles and their applications in medicine. Nanomedicine 2006, 1:157-168.

7. Fang C, Zhang MQ: Multifunctional magnetic nanoparticles for medical imaging applications. J Mater Chem 2009, 19:6258-6266.

8. Kaushik A, Khana R, Solanki PR, Pandey P, Alam J, Ahmad S, Malhotra BD: Iron oxide nanoparticles-chitosan composite based glucose biosensor. Biosensors and Bioelectronics 2008, 24:676-683.

9. McCarthy JR, Kelly KA, Sun EY, Weissleder R: Targeted delivery of multifunctional magnetic nanoparticles. Nanomedicine 2007, 2:153-167.

10. Yang Y, Bai YX, Li YF, Lei L, Chui YJ, Xia CG: Characterization of Candida rugosa lipase immobilized onto magnetic microspheres with hydrophilicity. Precess Biochem 2008, 43:1179-1185.

11. Lei L, Bai YX, Li YF, Yi LX, Yang Y, Xia CG: Study on immobilization of lipase onto magnetic microspheres with epoxy groups. J Magn Magn Mater 2009, 321:252-258.

12. Lee DG, Ponvel KM, Kim M, Hwang S, Ahn IS, Lee CH: Immobilization of lipase on hydrophobic nano-sized magnetite particles. J Mol Catal B Enzym 2009, 57:62-66.

13. Lee H, Dellatore SM, Miller WM, Messersmith PB: Mussel-Inspired Surface Chemistry for Multifunctional Coatings. Sci 2007, 318:426-430.

14. Lee H, Scherer N, Messersmith PB: Single-Molecule Mechanics of Mussel Adhesion. Proc Natl Acad Sci 2006, 103:12999-13003.

15. Lee H, Rho J, Holmburg K, Messersmith PB: Facile conjugation of biomolecules onto surfaces via mussel adhesive protein inspired coatings. Adv Mater 2009, 21:431-434.

16. Xu C, Xu K, Gu H, Zheng R, Liu H, Zhang X, Guo Z, Xu B: Dopamine as a robust anchor to immobilize functional molecules on the iron oxide shell of magnetic nanoparticles. J Am Chem Soc 2004, 126:9938-9.

17. Amstad E, Gillich T, Bilecka I, Textor M, Reimhult E: Ultrastable Iron Oxide Nanoparticle Colloidal Suspensions Using Dispersants with CatecholDerived Anchor Groups. Nanoletters 2009, 9:4042-4048.

18. Zhang L, Xue H, Gao CL, Carr L, Wang J, Chu BC, Jiang SY: Imaging and cell targeting characteristics of magnetic nanoparticles modified by a functionalizable zwitterionic polymer with adhesive 3,4-

dihydroxyphenyl- L-alanine linkages. Biomaterials 2010, 31:6582-6588

19. Liu Y, Simon JD: The effect of preparation procedures on the morphology of melanin from the ink sac of Sepia officinalis. Pigment Cell Res 2003, 16:72-80.

20. Wu JC, Ho P, Poh TY, Talukder MMR, Choi WJ: Enhanced enantioselectivity of immobilized Candida antarctica lipase for hydrolysis of ketoprofen ethyl ester at pH 1. Korean J Chem Eng 2007, 24:648-650.

21. Jiang YY, Guo C, Xia HS, Mahmood I, Liu CZ, Liu HZ: Magnetic nanoparticles supported ionic liquids for lipase immobilization: Enzyme activity in catalyzing esterification. J Mol Catal B Enzym 2009, 58:103-109.

22. Bradford M: A Rapid and sensitive method for the quantitation of microgram quantities of protein utilizing the principle of dye-binding. Anal Biochem 1976, 72:248-254

23. Bhushan I, Parshad R, Qazi GN, Ingavle G, Rajan CR, Ponrathnam S, Gupta VK: Lipase enzyme immobilization on synthetic beaded macroporous copolymers for kinetic resolution of chiral drugs intermediates. Precess Biochem 2008, 43:321-330.

doi:10.1186/1472-6750-11-63

Cite this article as: Ren et al:: Facile, high efficiency immobilization of lipase enzyme on magnetic iron oxide nanoparticles via a biomimetic coating. BMC Biotechnology 2011 11:63.

\section{Submit your next manuscript to BioMed Central and take full advantage of:}

- Convenient online submission

- Thorough peer review

- No space constraints or color figure charges

- Immediate publication on acceptance

- Inclusion in PubMed, CAS, Scopus and Google Scholar

- Research which is freely available for redistribution

Submit your manuscript at www.biomedcentral.com/submit
C Biomed Central 